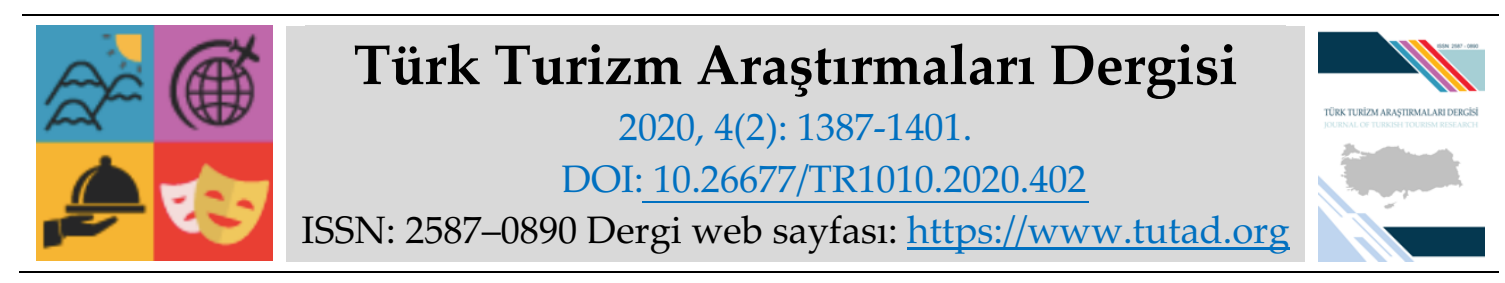

ARASTTIRMA MAKALESI

\title{
Gastronomi Özellikleri Açısından Türk ve Kazak Kültürü: Benzerlikler ve Farklılıklar Üzerine Bir Değerlendirme
}

Prof. Dr. Mehmet SARIIŞIK, Sakarya Uygulamalı Bilimler Üniversitesi, Turizm Fakültesi, Sakarya, e-posta: msariisik@subu.edu.tr ORCID: https://orcid.org/0000-0002-0681-6137

Urmanbek TAGMANOV, Doktora Öğrencisi, Sakarya Uygulamalı Bilimler Üniversitesi, Turizm Fakültesi, Sakarya, e-posta: ormanbek1991@gmail.com

ORCID: https://orcid.org/0000-0003-2960-9816

Öz

Bu çalışmanın amacı, Türk ve Kazak gastronomi değerlerini ve özelliklerini hammaddeler, yemek çeşitleri, mutfak ekipmanları, alışkanlıklar ve ritüellerdeki uygulamalar gibi farklı açılardan karşılaştırarak iki ülke mutfağı arasındaki benzerlikler ve farklılıkları ortaya çıkarmaktır. Bunun için iki mutfak kültürüne ilişkin derinlemesine bir literatür taraması yapılmış ve elde edilen veriler içerik analizi yöntemiyle değerlendirilmiştir. Değerlendirme sonucunda başta mutfak ve kiler düzeni olmak üzere sofra adabı ve yemek çeşitleri arasında önemli benzerliklerin olduğu tespit edilmiştir. İsimleri farklı olsa da yapılışları birbirine benzeyen önemli sayıda yemek olduğu dikkat çekmektedir. Farklılıklar açısından ise en önemli alan ritüellerdeki uygulamalar ile hammadde tercihleridir. At etinin değerli kabul edildiği Kazak mutfağını Türk mutfağından ayıran en önemli unsurlardan biri olduğunu söylemek mümkündür. Ayrıca zeytinyağı kullanımı Türk mutfağında yaygın iken Kazak mutfağında bu yağa ilgi oldukça düşüktür.

Anahtar Kelimeler: Türk Mutfak Kültürü, Kazak Mutfak Kültürü, Yöresel Yemekler.

Makale Gönderme Tarihi: 24.01.2020

Makale Kabul Tarihi: 02.04 .2020

\section{Önerilen Atıf:}

Sarışık, M. ve Tagmanov, U. (2020). Gastronomi Özellikleri Açısından Türk ve Kazak Kültürü: Benzerlikler ve Farklılıklar Üzerine Bir Değerlendirme, Türk Turizm Araştırmaları Dergisi, 4(2): 1387-1401.

(C) 2020 Türk Turizm Araştırmaları Dergisi. 


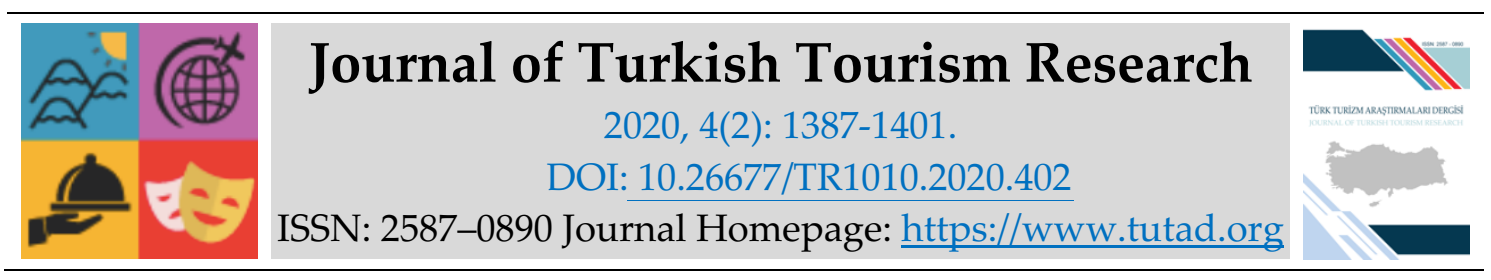

\title{
$\underline{\text { RESEARCH PAPER }}$
}

\section{Turkish and Kazakh Culture in of Gastronomy Properties: An Assessment on Similarities and Differences}

Prof. Dr. Mehmet SARIIŞIK, Sakarya University of Applied Sciences, Faculty of Tourism, Sakarya, e-mail: msariisik@subu.edu.tr ORCID: https://orcid.org/0000-0002-0681-6137

Urmanbek TAGMANOV, Ph.D. Student, Sakarya University of Applied Sciences, Faculty of Tourism, Sakarya, e-mail: ormanbek1991@gmail.com

ORCID: https://orcid.org/0000-0003-2960-9816

\begin{abstract}
The aim of this study is to reveal the similarities and differences between the two countries' cuisine by comparing the Turkish and Kazakh gastronomy values and properties from different aspects such as raw materials, food types, kitchen equipment, habits and practices in rituals. For this, an in-depth literature review of two culinary cultures was made and the data obtained were evaluated by content analysis method. As a result of the evaluation, it has been determined that there are important similarities between table manners and food types, especially kitchen and pantry order. It is noteworthy that, although their names are different, there are a significant number of dishes whose construction is similar. In terms of differences, the most important area is raw material preferences with applications in rituals. It is possible to say that it is one of the most important elements that distinguish Kazakh cuisine from Turkish cuisine, where horse meat is considered valuable. In addition, while olive oil use is common in Turkish cuisine, the interest in this oil is very low in Kazakh cuisine.
\end{abstract}

Keywords: Turkish Culinary Culture, Kazakh Culinary Culture, Local Foods.

Received: 24.01.2020

Accepted: 02.04.2020

\section{Suggested Citation:}

Sarışı1k, M. and Tagmanov, U. (2020). Turkish and Kazakh Culture in of Gastronomy Properties: An Assessment on Similarities and Differences, Journal of Turkish Tourism Research, 4(2): 13871401.

(C) 2020 Türk Turizm Araştırmaları Dergisi. 


\section{Gíriş}

Genel bir yaklaşımla kültür, bir ulusun ya da toplumun bir arada yaşamasına zemin hazırlayan maddi ve manevi olarak sahip olduğu, paylaştığı ve yaşattığı değerlerin tümü olarak açıklanabilir. Toplumun hayatını devam ettirebilmesi için temel gereksinimlerden olan yiyecek içeceklere ilişkin alışkanlık ve ritüeller de bu kültürün bir parçasıdır (Eren ve Sezgin, 2017: 161). Bilindiği üzere beslenme kültürü, içinde yaşanılan kültür, coğrafya, ekoloji, ekonom ve tarihsel süreçle birlikte şekillenmektedir. Bu açıdan beslenme kültürü, toplumun yaşam biçimiyle doğrudan bağlantılıdır (Aslan, Güneren ve Çoban, 2014: 5). İnsanın en temel biyolojik gereksiniminin de beslenme olduğunu söylemek mümkündür. Bununla birlikte beslenme insandan insana, bölgeden bölgeye ve ülkeden ülkeye farklı birçok unsurdan etkilenen bir kültür sistemidir. Bu sistem yeme içme kültürü olarak ifade edilmektedir (Bekar ve Zağralı, 2015: 41). Bu bağlamda yeme içme kültürünü, toplumun üyesi olan bireyler tarafından öğrenilen ve bir sonraki kuşağa aktarılan beslenme davranışlarının bütünü (Türk ve Şahin, 2004: 116) olarak açılamak mümkündür. Asırların birikimini ve çeşitliliğini taşıyan yeme-içme kültürü sadece beslenme odaklı olmayıp törenler, dini merasimler, düğünler ve eğlenceler gibi diğer kültürel faaliyetlerin de bir tamamlayıcısıdır (Sağır, 2012: 2676).

Neredeyse her millet tarihi geçmişi ile yeme-içme alışkanlıkları yer aldıkları coğrafi konum ve yetiştirilen tarım mahsullerine göre çeşitlilik gösteren bir mutfak kültürüne sahiptir (Eren ve Sezgin, 2017: 161). Bu açıdan ele alındığında mutfak kültürü; belirli bir coğrafyada yaşayan insanların beslenmesine uygun yiyecek içecekleri, bunların pişirilmesi ve korunması gibi süreçleri, ilgili uygulamalar ile kullanılan araç-gereçleri ve sofra adabı ile inanışları kapsayan bir kavramdır (Akdemir ve Selçuk, 2017: 795; Kesici, 2012: 34). Bölgelerin mutfak kültürleri tarih boyunca birçok aktörün etkisiyle biçimlenmiştir. Bölgesel yiyecek içecekler, o bölge kültürünün vazgeçilmez bir parçası olmakla birlikte ülke mutfağı hakkında bilgi sahibi olunmasını da sağlayan önemli kaynaklardır (Eren ve Sezgin, 2017: 161-162).

Yerel mutfak, bir bölgenin sahip olduğu yiyecek içeceklerin yanı sıra bunların hazırlanması, pişirilmesi, tüketilmesi, saklanması ve servis edilmesine ilişkin yöntemler ile kullanılan araç ve gereçler, mutfağın konumu, mimarisi, yemek törenleri ve bu çerçevede geliştirilen inanç ve uygulamalarından oluşan kendine özgü kültürel yapıyı açıklayan bir kavramdır (Toksöz ve Aras, 2016: 175). Bu mutfak içerisindeki yöresel yemekler bölgenin gelenek, görenek ve alışkanlıklarını, ekonomik olanaklarını, kendine özgü yemek hazırlama ve sunum biçimlerini kapsamaktadır (Altusaban, Yay ve Erdem, 2016: 238).

Dünyada hemen her millet kendi kültürel yapısına, beslenme alışkanlıklarına ve gelenekgöreneklerine göre oluşmuş bir mutfak kültürüne sahiptir (Akdemir ve Selçuk, 2017: 795). Kendi kültürü içinde şekillenen mutfak aynı zamanda etrafındaki gelişmeler ve ülke mutfakları tarafından da etkilenmiş̧tir. Örneğin pişirme sanatı Mezopotamya'da ortaya çıkmış ve ilerleyen süreçte Çin ve Asya mutfakları olmak üzere iki temel gruba ayrılmıştır. Çin mutfağının zenginliği ise Japon mutfağının oluşmasında önemli bir aktör olmuştur. Diğer taraftan Asya mutfağı Mısır mutfağını, Mısır mutfağı eski Yunan mutfağını, eski Yunan mutfağı Roma mutfağını, Roma mutfağı da Fransız mutfağının temellerini oluşturmuştur. Eski Yunan mutfağı İngiliz mutfağını da önemli ölçüde etkilemiştir. İngiliz mutfağı da özellikle Kuzey Avrupa ve Kuzey Amerika mutfaklarını etkisi altına almıştır (Düzgün ve Özkaya, 2015: 43).

Dünyada bir mutfağın en temel özelliklerinin tanınmışlık, özgünlük ve çeşitlilik olduğu belirtilmektedir. Tanınmışlık; bir mutfağa ait yemeklerin sunum ve sofra düzeninin diğer kültürlerce bilinmesi ve uygulanmasını, özgünlük, bir mutfak çerçevesinde üretilen yemeklerin, bu yemekleri üretme ve servis etme usullerinin tamamen o mutfağa ait olmasını, çeşitlilik ise bir 
mutfak kapsamında üretilen yemek sayısının zenginliğini açıklamaktadır (Mankan, 2012: 18). Zengin bir mutfak kültürüne sahip olmak o millete önemli avantajlar sağlamaktadır (Altusaban vd., 2016: 238). Yapılan bir değerlendirmede dünyanın en ünlü mutfakları arasında Çin, Fransız ve Türk mutfakları (Mankan, 2012: 18) gösterilmektedir. Türk mutfağı ağırlıklı olarak et, hamur işi, süt ve süt ürünleri gibi temel maddelere dayanmaktadır. Bu açılardan dolayı Kazak mutfağ ile önemli benzerliklere sahiptir. Ayrıca Türk-Kazak örf ve adetlerinin vazgeçilmez unsurlarından birisini misafirlerini üst düzeyde ağırlamak oluşturur. Daha önce de belirtildiği üzere bu çalışmada Türk ve Kazak mutfakları mercek altına alınmış ve ulaşılan bilgiler derlenmiştir. Bu bilgiler ışığında mutfak kültürünü oluşturan farklı aktörler üzerinden Türk ve Kazak mutfaklarındaki benzerlikler ve farklılıklar konusunda değerlendirmeler yapılmıştır.

Uzun yıllar ortak bir coğrafyada, ortak bir hayat paylaşan Türk boyları, bugün dünyanın dört bir tarafına dağılmışlar ve Orta Asya ve Avrupa'nın çeşitli kesimlerinde ayrı ayrı devletler kurmuşlardır. Günümüzde çeşitli Türk Cumhuriyetleri ve topluluklarında pek çok inanç, pratik, gelenek ve görenekler hala yaşamaktadır (Girgin, Oflaz ve Karaman, 2017: 101).

\section{LITERATÜR TARAMASI}

\section{Türk Mutfak Kültürü}

Türk mutfak kültürü, başka ülke mutfakları gibi, geçirdiği kültürel evreler, yaşadığı değişik coğrafyalar ve dini unsurlarla şekillenerek gelişmiş bir mutfaktır. Türk mutfak kültürünün Orta Asya'dan başlayıp Avrupa'ya kadar uzandığı bilinmektedir (Arlı ve Gümüş, 2007: 145). Türkler geçmişte Asya, Hint, Orta Doğu, Avrupa ve Afrika gibi çeşitli kültürlerle etkileşimde olduğundan Türk mutfağı da önemli zenginlik kazanmıştır. Anadolu'da 700 yıl boyunca hüküm süren Osmanlı İmparatorluğu, doğu ve batı arasındaki ana ticaret ağı olan İpek Yolu ile birlikte Avrupa, Kuzey Afrika ve Körfez'in önemli bir bölümlerini kontrol altına almıştır (Okumuş ve Çetin, 2015: 74). Bu bağlamda Türk mutfak kültürünün oluşumu, geçmişten bugüne farklı

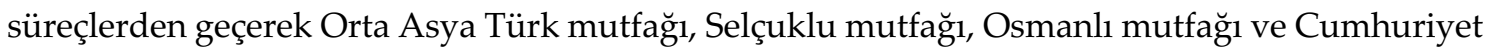
Dönemi mutfağı şeklinde ortaya çıkmıştır (Kurgun ve Özşeker, 2016: 122; Kızıldemir, Öztürk ve Sarışık, 2014: 193).

Orta Asya göçebe insanının et ve mayalanmış süt ürünlerini kullanmalarılyla başlayan süreç, Mezopotamya'da yetişen tahıllar ile Akdeniz'in sebze ve meyvelerine sahip olmaları ve Güney Asya'nın baharatını mutfaklarına alarak zengin bir Türk yemek kültürünü ortaya çıarmıştır (Şanlıer, Cömert ve Durlu Özkaya, 2012: 154). Yazılı belgeler Orta Asya'da yaşayan insanların temel uğraşlarının tarım ve hayvancılıktan oluştuğunu ispatlar niteliktedir. O dönemdeki yiyecekler daha çok buğday unuyla yapılmış yağlı hamur işleri ağırlıklıdır. Bununla birlikte Orta Asya Türklerinin beslenme alışkanlıkları, yaşadıkları bölgenin iklim şartları gereği hayvansal ürünler üzerine kurgulanmıştır. Özellikle, at, koyun, keçi ve diğer büyükbaş hayvanları yetiştirerek kurutulmuş et ürünleri, sütten ise yoğurt, tereyağı, ayran ve kımız gibi ürünler üretilerek tüketilmiştir (Kızıldemir vd., 2014: 194-195).

Selçuklularla birlikte Türk mutfak kültürü içinde yemek çeşitleri, pişirme ve muhafaza teknikleri ile kendilerine özgü bir mutfak kültürünün oluşumuna zemin hazırlamışladır (Önçel, 2015: 34). $\mathrm{Bu}$ dönemde de et ürünleri mutfakta önemli bir yer tutmaktadır. Özellikle, et yiyeceklerinde küçükbaş ve büyükbaş hayvanların etleriyle birlikte tavuk, ördek, kaz ve horoz gibi kümes ve av hayvanlarının etleri yaygın olarak kullanılmıştır. Bunlara ek olarak buğday unundan yapılmış ekmekler, meyve suları ve bal veya şekerden hazırlanan şerbetlerin de tüketildiği bilinmektedir 
(Kurgun ve Özşeker, 2016: 124-125). Selçuklular döneminde, kuşluk ve akşam (zevale) yemeği olmak üzere iki öğün bulunmaktadır. Kuşluk yemeğinde, yağlı hamur gibi tok tutan yiyecekler tercih edilerek akşam ögününde ise farklı yiyecekler tercih edilmekte ve güneş batmadan yenmektedir (Güler, 2010: 25).

Altı asır boyunca hüküm süren Osmanlı İmparatorluğu'nun Türk mutfak kültürünün oluşumunda önemli yeri vardır. Türk mutfak kültürünün oluşumunda altı asır boyunca hüküm süren Osmanlı dönemi önemli bir yere sahiptir. Çok ulusluluk, çok dinli anlayış ve üç kıtaya yayılan toprak hâkimiyetiyle Osmanlı İmparatorluğu, zenginliğini mutfak kültüründe de göstermiş ve mutfakta da kendine özgü bir zenginlik yaratmıştır (Düzgün ve Özkaya, 2015: 44).

$\mathrm{Bu}$ dönemde sultanlar, padişahlar ve devlet adamlarının yanı sıra yabancı konukları ağırlamak amacıyla farklı yiyecek içeceklerin hazırlanması için başvurulan yeni tarifler de Türk mutfağının zenginlik kazanmasına zemin hazırlamıştır (Bekar ve Zağralı, 2015: 42). Osmanlıda mutfak saray mutfağı ve halk mutfağı olmak üzere ikiye ayrılmaktadır. Saray mutfağı, padişah, Valide Sultan ve divan halkı için hazırlanmış gösterişli sofraları, halk mutfağ ise saray mutfağı kadar gösterişli olmasa da zengin çeşitlilikteki yiyecek içecekleri açıklamaktadır (Önçel, 2015: 35).

Cumhuriyet mutfağını, İstanbul mutfağı ve Anadolu mutfağı olarak iki bölümde incelemek mümkündür. İstanbul mutfağında yiyecek ve içecekler hem doyurucu hem de hafifken Anadolu mutfağında ise sofra adabı, pişirme teknikleri ve kışlık yiyecek içecekler dikkat çekmektedir (Kızıldemir vd., 2014: 202). Bunlar arasında döner, pide, lahmacun, simit, gözleme, köfte, börek, mantı, sarma, tandır, balık, pastırma, sucuk, peynir, zeytin ve sakatatlardan en çok bilinenleridir. Ayrıca Anadolu mutfağında çeşitli meyve ve sebzeleri, mercimek, nohut ve pirinç gibi kuru bakliyatları görmek de mümkündür. Öne çıkan çorba çeşitleri arasında en yaygın olanları mercimek, ezogelin ve tarhana çorbalarıdır (Kiliç, Çimen ve Ergün, 2018: 632). Son yıllarda çok tüketilen yiyecek içecekler arasına "fast food" olarak bilinen yeni bir yeme içme akımı da girmiştir. Bu akımın ortaya çıkmasının başlıca nedenleri arasında insanın zamanla yarışması, hızlı ve kolaylıkla yemek yeme ihtiyacını karşılaması gösterilmektedir. Bu nedenle insanların bu akıma ilgileri her geçen gün artmaktadır. Türk yemeklerinin birçoğunun hazırlanmasının uzun süre ve emek gerektirmesi, fast food akımına yönelimi hızlandırmış Türk yemeklerinin unutulmasına ve kaybolmasına zemin hazırlamıştır (Güler, 2007: 25).

Türkiye'nin her bölgesinin kendine özgü hammaddeleri, pişirme yöntemleri ve yeme içme kültürüne bağlı özgün bir mutfağa sahip olmasıyla birlikte bölgeler arasında önemli farklılıklar da dikkat çekmektedir (Ceylan ve Özçelik, 2018: 239; Güler, 2010: 28). Birçok bölgede Türk mutfak kültüründe halen devam eden özellikleri incelendiğinde; suda pişirme (haşlama, su buharında pişirme), yağda kızartma (az yağda ve çok yağda kızartma), kuru sıcaklıkta pişirme (fırında, sacda, közleme ve ızgara) ve yağ su karışımı pişirme yöntemlerinin yaygın olduğu görülmektedir (Halıc1, 2009: 36-37; Kurgun ve Özşeker, 2016: 128). Türk mutfak kültürüne yönelik daha net bilgiler elde etmek için yedi bölgenin temel özellikleri aşağıda özetlenmiştir (Heper ve Karaca, 2019; Ertaş ve Karadağ, 2013; Halıcı, 2009: 34-35).

Akdeniz Bölgesi Mutfağı: Akdeniz'de meyve ve sebze, baklagiller ve tahıllar, zeytinyağı, kırmızı et ve balık mahsulleri ağırlıklı olarak tüketilmektedir. Akdeniz bölgesinde Hatay (kâğıt kebabı, oruk, dövme, semirsek, zahter salatası ve künefe), Adana (bulgurlu çorba, Adana kebabı, şalgam suyu ve yufka), Mersin (tantuni ve cezerye) ve Isparta (oğmaç, sakalı sarkan çorbası, keşkek ve samsa) mutfak kültürleri önemli yer tutmaktadır.

Ege Bölgesi Mutfağı: Ege bölgesinde et, sebze, zeytinyağı ve hamur işleri yoğunlukla tüketilmektedir. İzmir (dalgan, İzmir köftesi), Muğla ve Denizli (kuru patlıcan dolması, patlıcan 
gözlemesi), Kütahya (kızılcık tarhanası, miyane çorbası), Afyonkarahisar (patlıcan böreği, kaymak) ve Uşak (Uşak tarhanası) mutfakları Ege bölgesinin simgesidir.

İç Anadolu Mutfağı: İç Anadolu yöresinde Sivas (pastırma, sucuk), Eskişehir (haşhaş, çiğ böreği, ekmek üğması), Konya (tirit, etli ekmek) ve Kayseri (pastırma, sucuk, mantı, aş makarna, su böreği) mutfakları ön planda gelmektedir. Bu yörede büyükbaş hayvan etleri, çeşitli sebzeler, meyveler ve çeşitli hamur işleri yoğun olarak tüketmektedir.

Karadeniz Bölgesi Mutfağı: Karadeniz bölgesinde balık (özellikle hamsi balığı), mısır ve mısır unu (mısır ekmeği), karalahana, fasulye, patates ve pirinç çok tüketilen ürünlerdendir. Rize (muhlama), Tokat (asma yaprağı, yaprak sarması, bacaklı çorba ve nivik) ve Kastamonu (Kastamonu simidi, hoşul pilavı, paça, üryani, hoşaf ve cevizli kadayıf) mutfakları başta gelmektedir.

Güneydoğu Anadolu Bölgesi Mutfağı: Bu bölgede hayvansal ürünleri ve baharat, acı biber, fasulye, nohut, mercimek, bezelye ve susam kuru baklagiller, lahana, karnabahar, maydanoz ve kuşkonmaz sebze ürünleri yaygın olarak tüketilmektedir. Bu bölgenin Gaziantep (çağla aşı, köfte, kebap, baklava), Şanlıurfa (çiğ köfte, kebap, bostana, şıllık) ve Adıyaman (gara şora, köfte, simitli köfte, parmak kebabı) mutfakları denilince akla ilk gelenlerdendir.

Doğu Anadolu Bölgesi Mutfağı: Bu bölgede büyükbaş et ürünleri, süt ürünleri (yoğurt ve çeşitli peynirler), tahıl ve hamur ürün işleri ilk sırada yer almaktadır. Kars (katmer, gagala, feselli, hingali Kars kaşarı, çeçil ve gravyer peyniri), Erzurum (çivil peynir, tirit, herle, lobiya, lesme çorbası, kadayıf dolması), Erzincan (turşu, börek, gasefe) ve Van (otlu peynir, kavut, çatçingir) mutfakları bu bölgenin simgeleri arasındadır.

Marmara Bölgesi Mutfağı: Marmara bölgesinde buğday, şekerpancarı, pirinç, zeytin, şeftali, kabak, çilek, domates, fındık, patates gibi sebze ve meyveler yetişmektedir. Trakya (Gaziler helvası), Tekirdağ (Tekirdağ köftesi, papaz mancası, elbasan tava, kesme makarna), Edirne (kuskus kapaması, yufkalı pilav, Rumeli lokması, piruhi, bulgurlu kol böreği, koçmak), Bursa (gavata, İnegöl, İskendeer kebabı, kestane, zürbiye), İstanbul (Çerkez tavuğu, Arnavut ciğeri, Tatar böreği, papaz yahnisi) mutfakları bu bölgede yer almaktadır.

Türk mutfak kültüründe geleneksel olarak 3.000'den fazla yiyecekler bulunmaktadır ve bu yiyecekleri içerik ve yapılış yöntemine göre çorbalar, kebaplar, yahniler, köfteler, sarma ve dolmalar, börekler, pilavlar, etli sebze yiyecekleri, zeytinyağll, sebze yiyecekleri, kurubaklagil yiyecekleri, kümes hayvanları, balık, yumurta yiyecekleri, salatalar, turşular, ekmekler ve tatlılar olarak sınıflandırma yapılabilir (Özdemir ve Kınay, 2004: 9).

Türklerin gıdaları ilk dönemlerde hayvansal ürünlerden oluşmuştur. Hayvancılık, Türk tarihi boyunca önemini korumuş, çoğu zaman en önemli, bazen de tek geçim kaynağı olmuştur (Aydoğdu ve Mızrak, 2017: 20). Türk mutfağında yaygın olarak koyun ve kuzu etleri, kümes hayvanları ve balıkları, ancak çok az dana ve sığır etleri tüketilmektedir (Halıc1, 2009: 36). Ayrıca domuz etini İslam dininde tüketmek yasak olduğu için ülke insanları tarafından tercih edilmemekte fakat ülkenin turizm potansiyeli açısından gelen turistlere bazı işletmelerde sunumu yapılmaktadır (Kızıldemir vd., 2014: 203). Koyun ve kuzu eti ile pişirilen şiş ve döner kebap gibi etli yiyecekler tüm dünyada adını duyurmuştur (Ertaş ve Karadağ, 2013: 120).

Tahıllar ve özellikle buğday Türk mutfağında önemli bir yere sahip olup bundan yapılan çok çeşitli yiyecekler bulunmaktadır. Özellikle ekmek Türk sofrasında sık tüketilen temel ürünlerden biridir. Buğday unundan börek, mantı, katmer, gözleme ve çörek gibi ürünler ile un çorbası, düğün çorbası, hamur çorbası ve kesme çorbaları gibi çorbalar da yapılmaktadır. Ayrıca pirinç ve bulgur pilavı da yaygın olarak tüketilmektedir (Baysal, 1996: 8-10). 
Süt ürünlerinden yapılan yağ, peynir, yoğurt ve ayran çeşitliliği Türk mutfağının zenginliğini ortaya çıkarmaktadır. Özellikle Türklerin yoğurdu sulandırılmış haline dönüştürülerek yaptıkları ayran en çok içilen içecektir (Birer, 1990: 252). Çay milli bir içecek olup küçük cam bardaklarıla servis edilmektedir. Kahve ise çaya göre daha sınırlı tüketime sahiptir. Türk kahvesi soğuk suyla içilir. Rakı da çok tüketilen alkollü içeceklerin birisi olarak dikkat çeker (Heper ve Karaca, 2019: 65). Türkler, çay ve Türk kahvesini genellikle tatlllarla birlikte tüketmektedir. Türk tatlıları hamur, tereyağı, fındık, fıstık, ceviz, kaymak ve şeker ağırlıklı olarak hazırlanmaktadır. Önemli tatlılar arasında baklava, şöbiyet, sarığıburma, bülbülyuvası, künefe ve helvalar dikkat çekerken özellikle Muharrem ayında aşure tatlılısı hazırlanmaktadır (Baysal, 1996: 14).

Çorbalar Türk mutfak kültüründe ilk yiyecek olarak sunulmakla birlikte her öğünde tüketilebilmektedir (Aydoğdu ve Mızrak, 2017: 20). Çorbaların büyük çoğunluğu tahıl, hamur veya unla, kuru baklagillerle, su ürünleriyle, et, sakatat ve kümes hayvanların etleriyle, süt ve sebze ürünleriyle hazırlanmaktadır (Arlı ve Gümüş, 2007: 151). Sebze ve meyve ürünleri de Türk mutfağında önemli bir yere sahiptir. Sebzeler etli, sadeyağlı, tereyağlı, zeytinyağlı ve tatlı olarak farklı amaçlarla kullanılabilmektedir. Salata, piyaz ve turşular diğer yiyeceklerle beraber sebze zenginliğini artırmaktadır. Meyveler bastı, yahni ve dolma gibi etli ve etsiz yemeklerde kullanılabilmekte ve ayrıca hoşaf, şerbet, komposto ve şurup yapımında değerlendirmektedir (Halıcı, 2009: 36). Yüzyıllar boyunca Türkler sebze ve meyveleri kurutarak ve konserve yaparak farklı ürünler ortaya çıkarmışlardır. Bu durumun tarımsal ekonomik yapı gereği kış yiyeceklerini hazırlamak kaygısından ortaya çıktı̆̆ açıktır (Birer, 1990: 252-253). Yiyeceklerin daha lezzetli olması için soğan, nane, domates salçası, maydanoz, kekik, reyhan, karabiber, kırmızıbiber, limon ekşileri ve zeytinyağı gibi tat vericiler mutfağın temel unsurlarıdır (Heper ve Karaca, 2019: 80-81; Baysal, 1996: 14-15).

Türk mutfağında üç öğün vardır ve aralarında en ağır olanı akşam yemeğidir. Yemekten önce ve sonra eller mutlaka yıkanır. Genellikle kırsal alanda yer sofrası yayılarak kentlerde ise masa düzeni hazırlanarak yemeğe "Besmele" ile aile büyüğü tarafından başlanır ve yemek bittikten sonra sofra duasını okunarak kalkılır. Yiyecekler ya kaşıkla ya da sağ elle yenir. Sofraya ilk önce çorba, sonra börek, yumurta ve pilav servis edilir. Ardından et veya etli sebze yemekleri ile eş zamanlı olarak zeytinyağlı yiyecekler getirilir. Ayran, şerbet, şurup, salata ve turşu gibi ek ürünler yemeğe göre servis edilir (Heper ve Karaca, 2019: 75-76; Halıc1, 2009: 30-32; Baysal, 1996: $4-5)$.

Türk mutfak kültüründe yeme içme törenler ve eğlenceler içerisinde de önemli paylaşım araçlarıdır. Yemekli önemli günler arasında ramazan, nevruz, hidrellez, doğum, sünnet, kına gecesi ve düğünler sayılabilir (Çakmak ve Sarışık, 2019: 5). Toylar, imece toplantıları, doğumlar, ölümler, düğünler ve nevruz kutlaması gibi pek çok tören sırasında yemek, ritüeli tamamlayan bir aktör olarak dikkat çeker. Bu toplantılarda geleneğe göre sofralar hazırlanmakta, yemekler ve içecekler üretilmekte, tüm oymak, boy veya köy insanlarıla beraber yemekle birlikte eğlenilmekte veya acılar paylaşılmaktadır (Sağır, 2012: 2682).

\section{Kazak Mutfak Kültürü}

Kazakistan'da Türklerin döneminde M.Ö. I. yüzyıldan itibaren göçebe yaşantıya bağlı olarak hayvancılık dikkat çeker. Yüzyıllar boyunca Orta Asya'da yaşayan Kazakların asıl mesleğinin hayvancılık olmasına rağmen tarım her bölgede farklı aşama ve zamanlarda gelişmiş, zamanla kaybolmaya yüz tutmuş ve sonra yeniden canlandırılmıştır. Kazakların ilk önceleri yerleştiği topraklarının sınırları, XV-XVI. yüzyıldan itibaren şekillenmeye başlamıştır. Buna bağlı olarak 
XIX. yüzyılın sonu ile XX. yüzyıla kadar Kazakların asıl mesleği hayvancılık olmuştur. XX. yüzyıl başlarından itibaren Rusların istilası nedenleriyle Kazakların belli bir kısmı göçebelikten yerleşik yaşama geçmeye başlamıştır (Katran, 2002: 19-23). Rus sömürgesinin arttığı dönemde (XIX. yüzyılın ikinci yarısı) ve Sovyet devrinde (XX. yüzyıl) Kazak halkının yemek kültürü tamamen değişime uğramış ve geleneksel yemek türlerinin çoğu unutulmaya başlamıştır. Özellikle, geçen yüzyılın 40-60'lı yıllarında Kazakların yemek menüsü tamamen değişmiştir. Geleneksel millî yemeklerin yerine Rus, Gürcü, Özbek, Uygur vb. Sovyetler Birliği içerisinde yaşayan milletlerin yemekleri yaygınlaşmaya başlamıştır (Turganbayev, 2019: 7).

Kazakların beslenme alışkanlıkları özellikle ekonomik yapı, coğrafya ve ülkenin etnografik özellikleri ile yakından bağlantılı biçimde ortaya çıkmıştır (Egizbaeva, 2012: 134). Ek olarak Kazak mutfağının farklı sosyal statü, ideolojik ilişkiler ve eski uygulamalardan da etkilendiği bilinmektedir (Alimbai, 2011: 269).

Kazakistan yüzölçümü açısından önemli bir büyüklüğe sahip olmasıyla birlikte çeşitli milletlerin tarihi ve kültürel mirasına da ev sahipliği yapmaktadır. Kültürel mirasın bir bölümü de turizm açısından önem taşıyan gastronomiye ilişkin öğelerdir. Kazak mutfağının tarihi ve bir bütün olarak Kazak toplumunun gelişimi ve oluşumu ile ayrılmaz bir şekilde bağlantılıdır (Sandybayev, 2019: 3).

Kazak halkının ana hammaddelerinin uzun süre et ve süt ürünleri oluşturmuştur. At ve koyun eti, kısrak, deve, koyun ve inek sütü ve bunlardan yapılan ürünler kazak sofrasına karakter vermiştir (Komarova, 1994: 295). Nüfusun tarım ve bahçecilikte büyümeye başladığı ve göçebelikten yerleşik yaşama geçtiği dönemde hayvan ürünlerinden hazırlanıp gelmiş ana yemekler ile birlikte ekmek çeşitleri, farklı meyve ve sebzeler tüketilmeye başlamıştır. Onların içinde en çok arpa, buğday ve pirinç dikkat çeker. En çok kullanılan meyveler ise frenküzümü, çilek, elma, armut, kuru üzüm, nar, sarımsak ve karabiberden oluşmuştur. Bununla birlikte güney bölgelerinde kavun, karpuz, havuç, pancar ve bitkisel yağlar yaygın olarak kullanılmaya başlamıştır. Sonuçta, patatesler ve domatesler Kazak mutfağına sonradan girmiştir. XVIII-XX yüzyıllarda, dünyadaki diğer kültürlerin yemekleri ve farklı hammaddeler kazak mutfağına eklenerek zenginleşmiştir (Kasimov, 1977: 6).

Kazak mutfak kültüründe et yemekleri, besin olarak hayvan ve av etlerin yenilebilir ve tüketilebilir parçalarından hazırlanan yemektir. Kazak mutfağında etsiz yemek neredeyse yok gibidir. Geleneksel yemekler günlük ögüunlerde bayram kutlamalarında ise koyun ve at etinin en değerli parçaları sofralarda yerini almaktadır. Beslenme konusunda et yemekleri soğuk dönemlerde ana enerji kaynağını olarak görülür. Yaz aylarında ise hayvancılık dışındaki ana gıda maddeleri süt ürünlerinden oluşur (Alimbai, 2012: 106).

Kazak mutfağının et yemekleri, süt ürünleri, tahıl yemekleri ve yemeklere tat verici olarak eklenen gıda maddelerinin kullanımında farklı teknikler mevcuttur. Et yemekleri başlıca üç yöntem ile yapılır. Bunlar kaynatma (haşlama), ızgara (isleme) ve kızartmadır (kavurma). En yaygını ise kaynatmadır (Alimbai, 2011: 270). Kazak yöresel mutfağında genellikle koyun, inek, deve, keçi ve at eti yemekleri hazırlanmaktadır. Kazaklar için at eti önemli yere sahip olup bu etten kazı (bir tür kalın sucuk), şucık (bir tür sucuk veya sosis), cal (bir tür haşlanmış ve dilimlenmiş et), karta (bir tür kalın sucuk) ve sur (kurutulmuş et) gibi geleneksel soğuk yöresel yemekler hazırlanılmaktadır (Bikenov, 2010: 97). Kazak mutfağı etten yapılmış yemekler ile önemli bir zenginliğe sahiptir. Et yemekleri arasında en önemlileri beşbarmak (hamurlu et yemeği), kazakşa et (etli çorba), mipilav (beyinli pilav), kazakşa bastırma (şiş kebap), et, kabak, havuç ve patates ile yapılmış mantı, tuşpara (pelmeni) ve kavurulmuş tuşpara (pelmeni), orama (sebze veya et dolgulu hamurişi) ve kespe (erişteli ve sebzeli çorba), ev ve bayram pilavları ve av etinden yapılmış kebaplardır (Tlemisov, 1995: 43-76). 
Daha önce belirtildiği gibi beşbarmak, Kazakların ana yemeklerinden birisidir. Kazakistan'ın farklı bölgelerine göre beşbarmak yemeği hazırlamada farklı malzemeler kullanılmaktadır. Pilavlar ev ve bayram pilavı olarak farklı pişirme yöntemleri ile hazırlanmaktadır. Çoğunlukla ev pilavı et ile yapılmaktadır. Bayram pilavı ise et, nohut ve üzüm ilave edilerek hazırlanır. Pilav genellikle kırmızı ya da sarı havuç eklenerek pişirilir. İki çeşit havuçla yapılan pilavın kendine has aroması mevcuttur. Pilav sadece Kazak mutfağına ait bir yemek olmayıp, Orta Asya ülkelerinde de yaygın olarak tüketilmekte ve her ülkenin kendine özgü pilav pişirme yöntemleri bulunmaktadır.

Kazaklar yabani hayvan ve kuş etini yemeklerinde sıkça kullanırlar. Bu nedenle geleneksel et yemeklerinde av eti önemli bir yere sahiptir. Dağkeçisi, argali, geyik ve sayga gibi yabani hayvanlar sonbaharda semirmiş (döllenmiş) döneminde avlanmaktadır (Egizbaeva, 2012: 135, Katran, 2002: 30). Kazaklar yabani hayvanları ve kuşları özgünlügüne ve yemeğin çeşidine göre kullanırlar. Et yemeklerinde kullanan hayvanlar ve yabani hayvanların seçiminde özel şartlar söz konusudur. $\mathrm{Bu}$ inanca dayalı olarak ortaya çıkmış helal ve haram kavramları dikkat çekicidir. İslam dini esasları çerçevesinde at ve eşek etini yemek mekruhtur. Bununla birlikte Kazak mutfağında at eti geleneksel yemek olarak dikkat çeker. Domuz eti ise haram kabul edilir (Alimbai, 2012: 107) .

Balık eti, Kazak mutfağında uzun süredir yemek olarak tüketilmektedir. Balıketi haşlama, yağda kızartma ve ızgarada pişirme teknikleriyle veya kurutularak değerlendirilmektedir. İslenmiş, tuzlanmış ve kurumuş balıklar tercih edilen yemek arasındadır. Batı ve Orta Kazakistan' da turna, sazan ve diğer iri balıklar et gibi ekmek karıştırarak hazırlanmaktadır (Alimbai, 2011: 402, Bikenov, 2010: 125). Örnek olarak, balık kespesi (balık eriştesi), kazakşa balık çorbası, kavrulmuş bekire (mersin balığı), balık pilavı ve balık kebebı (köftesi) gibi yiyecekler balık etinden yapılmaktadır (Tlemisov, 1995: 85-90).

Kazakların ulusal çorbaları ağırlıklı olarak farklı etler eklenerek yapılmaktadır. Çorbalarda genellikle inek, koyun, at ve deve etleri kullanılmaktadır. Ayrıca son dönemde av kuşları ve balık da kullanılmaya başlanmıştır. Temel olarak, çorbalar, çeşitli el yapımı kespeler (erişteler), bazen de tahıllar ilave edilerek hazırlanır. Neredeyse tüm çorbalar bol vitaminli olup lezzet verici yeşillikler katılarak tüketilmektedir (Bikenov, 2010: 106). Temel çorbalar kaynatpa çorba (etlisebzeli çorba), pirinçli-etli çorba, erişteli-etli çorba, kabaklı-etli çorba, tuşpara (pelmeni) çorbası ve yeşillik ilaveli tavuk çorbasıdır (Tlemisov, 1995: 85-90).

Hayvanlardan elde edilen bir diğer temel gıda maddesi ise süt ürünleridir. Eski teknolojiye dayanarak, sütten çeşitli yiyecekler içecekler üretilmektedir. Bu yiyecek içecekler pişirme, mayalama, ekşitme, çalkalama, süzme ve kurutma gibi yöntemler ile hazırlanmaktadır (Alimbai, 2011: 270). Bu yöntemlerle sütten uvız (bir tür peynir), kurt (yoğurtun kurutulmuş hali), peynir, ekşimik, tereyağı ve kaymak üretilmektedir. Ayrıca, Kazak mutfağı sütten hazırlanan soğuk içeceklerle de zengin bir mutfaktır. Soğuk içecekler arasında ayran mayalanmış sütten, katık'ı (yoğurt) kaymağı alınmamış sütten, şalap ise ayran veya şubata su ilave edilerek, şubat mayalanmış deve sütünden; aşı̆̆an köce mayalanmış ayrana bulgur ilave edilerek ve kımız ise kısrağın mayalanmış sütünden hazırlanmaktadır (Tlemisov, 1995: 23-35).

Sıcak içecek olarak çay, Kazak mutfağına XIX. yüzyılın başında girmiştir. Kazak mutfağına geç giren çayın farklı tüketim alanları ortaya çımıştır. Bunlar arasında sütlü çay, kara çay, yeşil çay, frenküzümü çay ve etli çay (içinde çay yaprağı bulunmayan bir tür et suyu) sayılabilir. Bu çayların birçoğu mevsimsel özellikleri bakımından farklılık göstermektedir. Bunların en yaygın tüketileni ise sütlü çaydır (Katran, 2002: 62).

Tahıl ve un ürünlerinden hazırlanmış yemekler kazak mutfağında günlük yiyecekler arasında önemli bir yer tutmaktadır. Tahıl ürünlerinden yiyecek üretimi geleneksel olarak üç kategoriye ayrılır. Birincisi ve en yaygın olanı kavurmadır. Bu yöntemle kavrulmuş darı, buğday, mısır ve 
çeşitli baklagiller gibi tahıl ürünlerinden farklı yemekler hazırlanır. İkinci yöntem kaynatmadır. $\mathrm{Bu}$ yöntemle çeşitli köce (göce-yarılmış/kırılmış buğdaydan yapılan yemek), botka (sütlü-tahıllı tatlı) ve bılamık (tereyağlı ve sütlü-tahıllı tatlı) gibi yemekler hazırlanır. Üçüncü yöntemde tahıl ürünleri ögüterek yemekler yapılır (Alimbai, 2011: 270).

Kazak mutfağında buğday büyük öneme sahip olup buğdaydan çeşitli kalitede un ürütmektedir. Ayrıca un, yemeklerin hazırlanma yöntemine göre ekşimiş (mayalanmış) ve ekşimemiş hamur olarak ikiye ayırılmaktadır. Genel olarak, un ürünlerinden tavada, bitkisel yağda kavurma ve buharda pişirme yöntemleriyle taba nan, tandır nan, şelpek, külşe, baliş, tokaş, bavursak, orama, cayma, kattama ve kuymak gibi ekmekler hazırlanmaktadır. Bununla birlikte, samsa ve tandır samsa (etli ekmek), mantı ve tüşpara gibi yemekler üretilmektedir (Katran, 2002: 64-67, Tlemisov, 1995: 95105).

Kazakların geleneksel yaşantısı göçebeliğe dayandığından meyve ve sebze gibi ürünleri ilk dönemlerde yetiştirmedikleri bilinmektedir. Göçebeliğe bağlı olarak doğal ortamdaki yenilebilir bitkiler ile et yemekleri ve çorbaları tat verici olarak kullanmışlardır. Ayrıca, sarımsak çeşitleri de sos olarak kullanılmıştır (Alimbai, 2011: 270).

Günümüzde elma, erik, akdiken, frenküzümü, ahududu, çilek ve diğer meyve çeşitleri yetiştirilmekte ve mutfaklarda yaygın olarak bilinmektedir. Meyveler, Kazak yemeklerinin önemli bir parçasıdır. Göçebe Kazaklar çoğunlukla yabani meyve türlerini kullanmışlardır. Aynı zamanda, özellikle güney bölgesindeki Kazak bozkırlarında bahçecilikle uğraşan Kazakların varlığı bilinmektedir. Yukarıda belirtilen meyvelere ek olarak, kavun, karpuz ve üzüm de yetiştirilmektedir. Çeşitli meyveler kurutulmaktadır. Özellikle kavun ve üzüm kuruları Kazaklar tarafından sıkça tüketilmektedir (Alimbai, 2012: 307-308).

Kazak sofrasında tatlı yemekleri en son çay eşliğinde servis edilmektedir. Kazak mutfağında çok sayıda tatlı çeşidi bulunmakla birlikte geleneksel mutfağın tatlı çeşitleri de yaşatılmaktadır (Komarova, 1994: 298). Bunlar arasında helva, kavun kuruyemişi, şak-şak (hamur ve sütten yapılan tatlı), şekerli ceviz, üzümlü ve elmalı tatlı baliştir (un ve sütten yapılan tatlı) en çok bilinenleridir. Soslar ise sütlü sosu, kaymak sosu, acı kaymak sosu ve üzüm ekşisidir (Tlemisov, 1995: 105-116).

Kazakların kahvaltı, öğle ve akşam yemeği olmak üzere üç öğünü vardır. Ayrıca yazın öğlenden sonra atıştırmalık yemek yeme alışkanlığı söz konusudur. Iç̧inde bulunulan şartlara göre yemek düzeni hane yemeği, alan yemeği ve cemiyet yemeği olarak üçe ayrılmaktadır. Cemiyet yemeği ise günlük, törensel ve bayram yemeği olarak üçe ayrılır (Alimbai, 2011: 271; Katran, 2002: 72). Daha önce de belirttiği gibi Kazakların geleneksel beslenme biçimi hane ve cemiyet yemeği olarak ikiye ayrılmıştır. Hane yemeği günlük ve misafir yemeği olmak üzere ikiye ayrılmaktadır. Günlük yemeğine aile, komşu ve davetsiz (rastgele) gelen misafirler katılır. Misafir yemeği ise yakın akraba ve komşular ile yapılan küçük kutlamalar olarak bilinmektedir. Cemiyet yemeği de neşeli ve kederli olaylara bağlı olarak eğlence veya cenaze merasimi olarak ikiye ayrılmaktadır (Bikenov, 2010: 126-127; Katran, 2002: 73).

Kazaklarda sofra üzerinde kendine özgü oturma ve yerleşme sistemi vardır. En saygın ve yaşlı insanlar sofranın onurlu yerine otururlar. Sağ tarafa erkekler, sol tarafa ise kadınlar yerleşir. Kadınlar tarafına ocak tarafı adı da verilmektedir. Büyüklere saygı gösterilir. Yaşlılar yemeklerin tadına baktıktan sonra diğerleri yemeye başlar (Alimbai, 2011: 609-610). Yemekten önce ve sonra mutlaka eller yıkanır. Yemeğe besmele ile başlamakta ve sağ elle yenilmektedir. Birden fazla kişi bir tabaktan yemek yiyorsa adet gereği tabağın kendine yakın olan tarafından yer. Ağzı dolu olarak konuşmak saygısızlık işaretidir. Yemek yedikten sonra peçete kullanılır. Eller yıkanıp kurutulduktan sonra "besmele ve Allah hayırlı etsin" diyerek dua edilir. Kazaklarda yemekten 
önce ve sonra mutlaka dua edilmektedir (Bikenov, 2010: 130-131). Kazakistan'da resmî ve dinî bayramlarda Ahıska Türkleri, Kazak ve ülkede yaşayan diğer halklarla birbirlerinin bayramlarını karşılıklı kutlarlar. Nevruz bayramında şenliklerde Ahıska Türkleri de Kazak ve diğer halklarla beraber açılan çadırlarda kendi kültüründen ve mutfağından örnekler sergilemektedir (Güzeloğlu, 2017: 28).

\section{YÖNTEM}

Bu çalışmada nitel araştırma yöntemlerinden yararlanılmıştır. Öncelikle ilgili alanda yazın taraması yapılmış ve bu yolla iki mutfağa ait sofra adabına, öğünlerine, özel gün ve törenlerine, yemeklerine ve pişirme yöntemlerine ilişkin temel özellikler belirlenmeye çalışılmıştır. Elde edilen veriler gözden geçirilerek Türk ve Kazak mutfak kültürlerinin benzer ve farklı yanları tespit edilmeye çalışılmıştır. Elde edilen bilgiler içerik analizi ile değerlendirilmiştir. Bu bakımdan araştırmanın tarama betimleyici nitel bir araştırma olduğu söylemek (Yıldırım ve Şimşek, 2013: 259) mümkündür.

\section{BULGULAR}

\section{Türk ve Kazak Mutfak Kültürlerinin Benzer Yönleri}

Sofra adabı ve düzeni: İki bölge mutfağında da sofra adabı ve düzeni önemli bir ritüel olarak dikkat çekmektedir. Türk ve Kazak mutfağında yer ve masa sofrası düzeni söz konusudur. İki mutfakta da yer sofrası kırsal alanlarda hala devem etmekte birlikte masada da yemek söz konusudur. Şehirlerde ise yer sofrası yerine masa düzeni daha sık kullanmaktadır. Türk ve Kazak sofra adabında yemekten önce ve sonra eller mutlaka yıkanır. Büyükler oturmadan küçükler oturmaz ve büyükler yemek yemeye başlamadan önce küçükler başlamaz. İki millette İslam inancına sahip olduğundan yemeği besmele ile başlayıp dua ile bitirirler.

Öğünler: Türk ve Kazak mutfak kültürlerinde yemek öğünleri de benzerlik gösterir. Türk mutfağında kahvaltıda çoğunlukla zeytin, peynir, tere yağa ve çay gibi ürünler tercih edilir. Kazak mutfağında ise süt ve sütten yapılan tereyağı, botka, reçel ve çay gibi ürünler tüketilmektedir. Öğle yemeğinde iki mutfakta da ana yemekler bulunur. Akşam yemeğinde Türklerde çorba ve pilav ile birlikte ana yemek tercih edilir. Yemekten sonra çay ile tatlı tüketilir. Kazak mutfağında ise akşam öğününde pilav, çorba ve hamur yemekleri yaygındır.

Mutfak Sistemi: Türk ve Kazak evlerinde mutfak için özel bölüm ayrılmıştır. Kazakistan'ın bazı bölgelerinde mutfak "ocak" adıyla bilinir. Her iki kültürde olduğu gibi fırınlar dışarıda hatta evden ayrı olarak da yerleştirilebilir. Kiler ise yiyeceklerin, mutfakta günlük gerekli olan malzemelerin ve araç-gereçlerin saklandığı yerdir. Türk ve Kazak mutfaklarının birbirine olan benzerliği nedeniyle kilerde bulunan malzemeler ve araç-gereçler de benzerlik göstermektedir. Söz konusu araç ve gereç arasında her iki mutfakta bıçaklar, tahta kaşıklar, çatallar, hamur açma tahtası, oklava, tas, tava, tencere ile tuz, şeker ve biber gibi ürünler bulunmaktadır.

Özel Gün ve Törenler: Kazak mutfağında Nevruz bayramında nevruz köcesi, bauırsak, orama ve kattama gibi geleneksel yemekler tüketilir. Bununla birlikte doğum, sünnet, nişan-düğün, ölüm gibi neşeli ve kederli günlerde de çeşitli yiyecekler hazırlama ve sunma geleneği vardır. Düğünlerde at etinden yapılan kazı, karta ve içeceklerden kımız ve şubat gibi ürünlerle masalar hazırlanır. Dügünlerde özellikle etli çorbalar, beşbarmak, pilav ya da mantı servis yapılır. Tatlılardan kuymak, şak-şak vb. yiyecekler olur. Dügüun, sünnet ve milli günlerde koyun ve inek 
başı saygın misafirlere ikram edilir. Cenazelerde 7 gün, 40 gün ve yıl bazında yemek ikram edilir. Türk mutfağında da özel gün ve törenlerde yemekler önemli bir yere sahiptir. Doğum, sünnet, nişan-dügün ve ölüm merasimi gibi önemli günlerde genellikle çorbalar, et yemekleri, pilavlar, salata ve tatlı yemekleri sunulmaktadır. Düğün süreci içerisinde dışarıdan gelenlere sunulan çok çeşitli yemek ve gösterilen saygı (Kapağan ve Bacaklı, 2017: 735) her iki mutfakta da ortaktır.

Yemekler: Türk ve Kazak mutfak kültürlerinde yemek pişirme yöntemleri -kaynatma, kavurma, buharda pişirme gibi- hemen hemen aynıdır. Türk ve Kazak mutfağının yemeklerine ilişkin benzerlikler aşağıda özetlenmiştir:

- Çorbalar: Türk ve Kazak mutfağında etten, tahıldan ve süt üründen yapılan bazı çorbalar benzer özelliklere sahiptir. Yoğurt karıştırarak etli sebzeli çorbalar, sebzeli çorbalar, buğday, pirinç, bulgurdan yapılan çorbalar ve kesme çorbası gibi hamurdan yapılan çorbalar bunların arasında dikkat çekenleridir.

- Etli yemekler: Kavurma iki mutfakta da hazırlanan temel yemektir. Kazaklarda kavurma "kuırdak" olarak bilinir. Yapılış yöntemleri da neredeyse aynıdır. Koyun, kuzu, kümes hayvanları ve balıketinden yapılan çeşitli şiş ve kebap yemekleri de benzerlikler gösterir.

- Tahıldan yapılan yemekler: Pirinçten yapılan Kayseri pilavı ile Kazak pilavı yapılış yöntemi ve içindeki malzemeleri açısından benzerdir. Kavrulmuş ve kaynatılmış buğday, bulgur ve mısır gibi tahıldan yapılan yemeklerden de söz edilebilir.

- Hamurdan yapılan yemekler: Hamurdan yapılan yemekler her iki mutfakta da önemli yere sahiptir. Türklerdeki mantı, Kazak mutfağındaki tüşpara yemeğine benzemektedir. Yapılışı hemen hemen aynıdır. Bu yemeğin kaynatılmış ve kavrulmuş çeşitleri vardır. Türk mutfağındaki gözleme ve katmer gibi ekmekler Kazak mutfağındaki kattama ve şelpek ekmekleriyle benzemektedir.

- Tatlılar: Kazak mutfağındaki botka tatlısı Türk mutfağındaki sütlaç ile yapılış yöntemi ve malzeme açısından benzerdir. Kazakistan'da pirinç, buğday ve talkan (yulaf ezmesi) ürünleri sütle karıştırarak botka tatlısı yapılır.

- Sebze ve Meyve: Türk ve Kazak mutfak kültürlerinde sebze ve meyve ürünleri yaygın kullanılır. Bu ürünler yemeklerle birlikte pişirilir ya da çeşitli salatalar yapılır.

\section{Türk ve Kazak Mutfak Kültürlerinin Farklı Yönleri}

Yemekler: Türk mutfağında Kazak mutfağına göre zeytin ve zeytinyağı daha çok tüketilmektedir. Türk mutfağında özellikle zeytin ürünleri her ögünde bulunur ve bazı yemekler zeytinyağıyla yapılır. Kazak mutfağında ise ayçiçek ve kuyruk yağı daha yaygın kullanılır. Türk mutfağı tatlı yemekleri açısından Kazak mutfağına göre daha zengin durumdadır. Türk mutfağında rakı olarak bilinen alkollü içecek yaygın olarak tüketilmektedir. Kazak mutfağında ise at, kısrak ve deve sütünden yapılan kımız, şubat ve kımran gibi içecekler tüketilir.

Özel Gün ve Törenler: Türklerde kız (gelin) isteme merasiminde damada tuzlu Türk kahvesi sunulurken, Kazaklarda damada hayvanın tös eti (döş eti) yedirilir. Bununla birlikte, Kazaklarda dügün, sünnet ve ölüm merasimlerde saygın insanlara, yaşlı ve büyüklere hayvanın başı ikram edilir. Bunu Kazaklarda "Baş Tartu", yani "Baş İkram" adı verilir. Türk mutfağında ise at eti tüketilmez. 


\section{SONUÇ VE ÖNERİLER}

Türkler ve Kazaklar Orta Asya'dan gelen Türk aileleri olarak dili, dini, medeniyeti ve hatta mutfak kültürleri benzer özellikler taşıyan iki devlet tek millet niteliğindedir. Ancak Türkler Anadolu'dayken Ortadoğu ve Balkan ülkelerinin mutfak kültürlerinden etkilenerek daha zengin bir konuma gelmişlerdir. Kazak mutfağ ise doğuda Çin, kuzeyde Rusya, güneyde Hindistan ve batıda Arap yemek kültürlerinden etkilenmiştir. Bununla birlikte Orta Asya' da yaşayan Özbek, Uygur, Tatar ve Dungan gibi milletlerin mutfak kültürlerinden de etkilenmiştir. Bu etkileşime ve asırlarca zaman geçmesine rağmen Türk ve Kazak mutfak kültürlerinde kullanılan mutfak araç gereçleri, yemeklerin pişirme yöntemleri, çeşitliliği, kullanılan malzemeler, ürünler, gelenek ve görenekler, özel gün ve törenleri ile sofra adabına kadar uzanan birçok konuda benzer tarafları bulunmaktadır. Kazakların üç asırdır Rusların asimilesine uğramalarına rağmen dinini, dilini, gelenek ve göreneklerini ve hatta mutfak kültüründe bulunan tüm özelliklerini özgün şekilde koruduğu söylenebilir. Türk ve Kazak mutfak kültüründe yemekler ile özel gün ve törenler açısından bazı farklılıklar da bulunmaktadır. Bu farklılıklar daha çok özel törenlerde ortaya çıkmaktadır. Örneğin; sünnet, dügün ve milli merasimlerde koyun, inek kelleri ve paça kısımları kaynatma usulüyle pişirilerek saygın, yaşlı veya güç sahibi kimselerden başlayarak servis edilir. Ayrıca pozitif ayrımcılıktan kaynaklı olarak kadınlara ve çocuklara ayrı ayrı et parçaları ikram edilir. Türklerde kız isteme merasiminde damada tuzlu kahve ikramı yapılırken kazaklarda ise döş eti ikram edilir. Bu döş eti olmadan merasim gerçekleşmez. At etinden kazı, karta, sucuk gibi önemli ürünler hazırlanır ve kullanılır. Türk kültüründe ise at eti yenilmez ve herhangi bir alanda kullanılmaz. İçecek kültürü açısından çay tüketiminde de farklılıklar söz konusudur. Yeşil çay Kazak kültüründe önemli bir yere sahipken Türk kültüründe ise siyah çay tercih edilir. Ayrıca sütlü çay Kazak kültüründe önemlidir. Siyah çay mutlaka süt ile birlikte servis edilip içilir. Kazak kültüründe deve ve kısrak gibi süt ürünlerinden kımız, şubat ve kımran soğuk içecekler hazırlanır.

Genel bir değerlendirme yapıldığında tüm gastronomi unsurları açısından iki mutfağın farklılıklardan daha çok yakın özelliklere sahip olduğu söylenebilir. Her ne kadar Kazakların bulunduğu topraklara yerleşmesi ve Türklerin Anadolu'ya göç etmesi iki mutfağ zenginleştirmesi kadar farklı özelliklere sahip olmasına zemin hazırlasa da Türk milletine özgü yemekler ve gelenekler hala sürdürülmektedir. Bu benzerlik sadece Kazak ve Türk mutfakları arasında değil tüm Türk devletlerinde söz konusudur.

Geçmişte sınırlı yazına sahip Türk mutfağı ve diğer Türk Cumhuriyetlerine ilişkin detaylı ve kalıcı eserlerin hazırlanması hem geleceğe aktarımda hem de temel mutfak kültürünün yaşatılması açısından önem arz etmektedir. Türk devletleri mutfaklarına ilişkin detaylı benzerlik ve farklılık raporlarının hazırlanmasına ilişkin çalışmaların da desteklenmesi gerekir.

\section{KAYNAKÇA}

Akdemir, N. ve Selçuk, G. N. (2017). Mutfak Kültürünün Sürdürülebilirliği Bakımından Yöresel Yiyeceklerin Menülerde Yer Alma Düzeyi: Taraklı Ölçeğinde Bir Araştırma. I. International Sustainable Tourism Congress, 23-25 November 2017. Kastamonu.

Alimbai, N. (2011). Kazaktın Etnografiyalık Kategoriyalar, Uğımdar men Ataularının Dasturli Cuyesi. Ensiklopedia, 1, Almatt: DPS.

Alimbai, N. (2012). Kazaktın Etnografiyalık Kategoriyalar, Uğımdar men Ataularının Dasturli Cuyesi. Ensiklopedia, 2, Almatı: RPK Slon.

Altusaban, S., Yay, Ö. ve Erdem, Ö. (2016). Yöresel Mutfak Kavramına İlişkin Şeflerin Bakış Açlarının Değerlendirilmesi, II. Rize Turizm Sempozyumu, 4-6 Kasım 2016. Rize. ss. 237-261. 
Arlı, M. ve Gümüş, H. (2007). Türk Mutfak Kültüründe Çorbalar. Uluslararası Asya ve Kuzey Afrika Çalışmaları Kongresi, 10-15 Eylül 2007. Ankara.

Aslan, Z., Güneren, E. ve Çoban, G. (2014). Destinasyon Markalaşma Sürecinde Yöresel Mutfağın Rolü: Nevşehir Örneği, Journal of Tourism and Gastronomy Studies, 2(4): 3-13.

Aydoğdu, A. ve Mızrak, M. (2017). Azerbaycan ve Türkiye Mutfak Kültürünün Tarihi Birlikteliği ve Mevcut Durumunun Belirlenmesi, Uluslararası Türk Dünyası Turizm Araştırmaları Dergisi, 2 (1): $15-25$.

Baysal, A. (1996). Türk Mutfağından Örnekler. Ankara: T.C. Kültür Bakanlığı.

Bekar, A. ve Zağralı, E. (2015). Türk Yemek Kültürü ve Teknolojik Gelişmelerin Yemek Kültürü Üzerine Etkileri, Journal of Tourism Theory and Research, 1(1): 40-48.

Bikenov, A. (2010). Kazaktın Materialdık Madenieti. Astana: Filiant Baspası.

Birer, S. (1990). Türk Mutfağının Tarihsel Gelişim Sureci İçerisindeki Değişimi ve Bugünkü Durumu, Beslenme ve Diyet Dergisi, (19): 251-260.

Ceylan, J.A. and Ozcelik, A. O. (2018). Cuisine Culture of the Pearl of Mesopotamia: Mardin, Turkey, Journal of Ethnic Foods, (5): 239-245.

Çakmak, M. and Sarışık, M. (2019). An Investigation on the Basic Contents of the Main Dishes of the Turkish Cuisine, Anais Brasileiros de Estudos Turisticos, 1-13.

Düzgün, E. ve Özkaya, F. D. (2015). Mezopotamya'dan Günümüze Mutfak Kültürü, Journal of Tourism and Gastronomy Studies, 3(1): 41-47.

Egizbaeva, M.K. (2012). Kazak Halkının Dasturli Tağamdanu Cuyesi, History of the Homeland Research Journal, 2 (58): 134-137.

Eren, Y. F. ve Sezgin, C. A. (2017). Gastronomi Turizmi Açısından Mersin Yöresi Mutfak Kültürünün Sürdürülebilirliği. I. International Sustainable Tourism Congress, 23-25 November 2017. Kastamonu.

Ertaş, Y. ve Gezmen-Karadağ, M. (2013). Sağlıklı Beslenmede Türk Mutfak Kültürünün Yeri, Gümüşhane Üniversitesi Sağlık Bilimleri Dergisi, 2 (1): 117- 136.

Girgin, G. K., Oflaz, M. ve Karaman, N. (2017). Türk Cumhuriyetlerinden Gelen Öğrencilerin Türk Mutfağı Hakkındaki Görüşlerinin Belirlenmesi, MANAS Sosyal Araştırmalar Dergisi, 6 (5): 95-111.

Güler, S. (2007). Türk Mutfağının Değişim Nedenleri Üzerine Genel Bir Değerlendirme. I. Ulusal Gastronomi Sempozyumu ve Sanatsal Etkinlikler, 4-5 Mayıs 2007. Antalya. ss:18-28.

Güler, S. (2010). Türk Mutfak Kültürü ve Yeme İçme Alışkanlıkları, Dumlupınar Üniversitesi Sosyal Bilimler Dergisi, (26): 24-30.

Güzeloğlu, C. (2017), Kazakistan'da Çimkent Bölgesinde Sürgünde Yaşayan Ahıska Türklerinin Kültür çatısı: Doğum, Düğün, Ölüm Adetleri, Yayımlanmamış Yüksek Lisans Tezi, Ardahan Üniversitesi, Ardahan.

Halıcı, N. (2009). Türk Mutfağı. (1. Basım), İstanbul: Oğlak Yayınları.

Heper, Ö.F. ve Karaca, E. (2019). Uluslararası Gastronomi, (Editör) Sarışık M.: Türk Mutfă̆̊ (5. Basım, ss.61-76) Ankara: Detay Yayıncılık.

Kasimov, S. (1977). Kazaktın Ulttık Tağamdarı. Almatı: Kaynar. 
Kapağan, E. ve Bacaklı, Y. (2017). Kazak Türklerinde Terbiye Edici Bir Unsur Olarak Alkış ve Batalar, Insan ve Toplum Bilimleri Araştırmaları Dergisi, 6 (2): 731-740.

Katran, D. (2002). Kazaktın Dasturli As-Tağam Madenieti: Tarihi-Etnografiyalık Zerttev, Monografiya, Almatı: KazMÖĞZİ.

Kesici, M. (2012). Kırsal Turizme Yönelik Olan Yöresel Talepte Yiyecek ve İçecek Kültürünün Rolü, KMÜ Sosyal ve Ekonomik Araştırmalar Dergisi, 14 (23): 33-37.

Kızıldemir, Ö., Öztürk, E. ve Sarışık, M. (2014). Türk Mutfak Kültürünün Tarihsel Gelişiminde Yaşanan Değişimler, AİBÜ Sosyal Bilimler Enstitüsü Dergisi, 14(3): 191-210.

Kiliç, G., Çimen, H. ve Ergün, B. (2018). Traditional Afyonkarahisar Cuisine and Local Dishes. Social Sciences Researches in the Globalizing World, St. Kliment Ohridski University Press. Sofia.

Komarova, T.A. (1994). Tamaktanu Alippesi. Almatı: Kaynar.

Kurgun, H. ve Özşeker, D. (2016). Gastronomi ve Turizm. Ankara: Detay Yayıncılık.

Mankan, E. (2012). Yabancı Turistlerin Türk Mutfağına İlişkin Görüşleri: Ege Bölgesi Örneği, Yayınlanmamış Doktora Tezi, Ankara Üniversitesi, Ankara.

Okumus, B. and Cetin, G. (2015). Using Local Food in İstanbul's Marketing as a Tourist Destination. Proceeding of the IV. International Interdisciplinary Business-Economics Advancement Conference, 26-29 May 2015. Las Vegas, Navada, USA.

Önçel, S. (2015). Türk Mutfağı ve Geleceğine İlişkin Değerlendirmeler, Journal of Tourism and Gastronomy Studies, 3(4): 33-44.

Özdemir, B. ve Kınay, F. (2004). Yabancı Ziyaretçilerin Türk Mutfağına İlişkin Görüşleri: Antalya'yı Ziyaret Eden Alman ve Rus Turistler Üzerine Bir Araştırma, Gazi Üniversitesi Ticaret ve Turizm Eğitim Fakültesi Dergisi, 2: 5-28.

Sağır, A. (2012). Bir Yemek Sosyolojisi Örneği Olarak Tokat Mutfağı, Electronic Turkish Studies, 7(4): 2675-2695.

Sandybayev, A. (2019), Innovative Gastronomic Tourism as a New Trend. Evidence from Kazakhstan, International Journal of Research in Tourism and Hospitality, 5(1): 1-7.

Şanlıer, N., Cömert, M. ve Durlu Özkaya, F. (2012). Gençlerin Türk Mutfağına Bakış Açısı, Milli Folklor, 24 (94): 152-161.

Tlemisov, H. (1995). Kazaktın Ülttık Tağamdarı. Almatı: Kaynar.

Toksöz, D. ve Aras, S. (2016). Turistlerin Seyahat Motivasyonlarında Yöresel Mutfağın Rolü, Journal of Tourism and Gastronomy Studies, 4(1): 174-189.

Turganbayev, A. (2019). Kazakların Geleneksel Mutfak Kültürü ve Hızlı Yemek Sistemi (Fast Food), I. Uluslararası Türk Dünyası Tarım ve Gıda Sempozyumu, 19-21 Aralık 2019, İzmir.

Türk, H. ve Şahin, K. (2004). Antakya Geleneksel Yemek Kültürü, Mustafa Kemal Üniversitesi Sosyal Bilimler Enstitüsü Dergisi, 1 (2): 115-132.

Yıldırım, A. ve Şimşek, H. (2013). Sosyal Bilimlerde Nitel Araştırma Yöntemleri. (9. Basım), Ankara: Seçkin Yayıncılık. 